\title{
Monetary Incentives in Italian Public Administration: A Stimulus for Employees? An Agent-Based Approach
}

\author{
Linda Ponta $\mathbb{D D}^{1},{ }^{1}$ Gian Carlo Cainarca $\mathbb{D}^{2},{ }^{2}$ and Silvano Cincotti $\mathbb{D}^{2}$ \\ ${ }^{1}$ LIUC-Cattaneo University, Corso G. Matteotti 23, I-21053 Castellanza, VA, Italy \\ ${ }^{2}$ DIME-DOGE, University of Genoa, Via Opera Pia 15, I-16145 Genova, Italy \\ Correspondence should be addressed to Silvano Cincotti; silvano.cincotti@unige.it
}

Received 7 February 2020; Accepted 22 April 2020; Published 23 May 2020

Academic Editor: Dehua Shen

Copyright (c) 2020 Linda Ponta et al. This is an open access article distributed under the Creative Commons Attribution License, which permits unrestricted use, distribution, and reproduction in any medium, provided the original work is properly cited.

The paper, focusing on the context of Public Administration (PA), addresses the effects of monetary incentives in employees' performance. In the Italian PA, the monetary incentives are distributed according to the D.L.150/09 (i.e., the monetary incentives are divided among the employees according to the employees' performance) which is based on the rank order tournament. The paper investigates if this mechanism has positive and sustainable impacts on the employees' performance in the short, middle, and long term. The employees' performance has been modeled as a function of ability and motivation. The results of the computational experiments show a positive impact of the monetary incentives, distributed according to merit criteria, on the employees' performance in the short, middle, and long term.

\section{Introduction}

Starting from the late 1970s many European countries have experienced a period of reforms in the public sector. The reforms regarded different fields and in particular from one side the management system, introducing control and planning system, and from the other the performance appraisal and the reward systems, fostering technical and cultural changes in the public sector [1-8]. In Italy, since the early 1990s, numerous reforms have been succeeded with the purpose of reaching a better use of the resources and a better quality of services given to citizen. It is worth noting that reforms in Italy are characterized by a "top-down" approach, i.e., by regulation, and the most important are D. Lgs. 29/ 1993 and Law n. 59/97 (so called Legge Bassanini). These reforms tried to adopt new managerial instruments usually used in the private sector, but the results were a failure because the transferability of these instruments to the bureaucracy of the Public Administration (PA) is not always effective. The main causes of the failure were the constraints of PA, such as the possibility to make change only by means of laws and the uncertainty of the amount of resources. The last attempt of reform is the "Decreto Legislativo 27 ottobre
2009, n. 150," "Attuazione della legge 4 marzo 2009, n. 15, in materia di ottimizzazione della produttività del lavoro pubblico e di efficienza e trasparenza delle pubbliche amministrazioni. (09G0164)," also called Brunetta reform, where a virtuous circle able to induce behaviors more efficient to overcome the previous failure is initiated giving instruments extremely concrete and ready to use. Following the New Public Management theory (NPM), the Brunetta reform considers the PA as firms and borrows from the firm context the key concepts of efficiency, efficacy, productivity, and transparency. In particular, the efficiency connects the resources used (input) with the results (output); the transparency means the possibility of the citizen to access to the activity of PA; the efficacy considers the measure of the action of the PA on the external environment; and finally the productivity means the performance of the employees and of the organization. In fact, according to NPM, performance management based on objectives, monitoring, and incentives must be introduced in public sector organizations [6]. Focusing on the incentives and in particular on the monetary incentives given to the employees, according to D.L. $150 / 09$ the incentives are no more divided equally among the employees but they are distributed only to the employees 
that perform better, ranking them according to merit criteria. In fact, as stated in [9, 10], pay-for-performance systems are less efficient than the promotion tournaments in public organizations.

The main goal of the paper is to verify the effects of the new incentives mechanism introduced with D.L.150/09 in the Italian PA and to observe its sustainability over time. In order to address such investigation, the paper presents an agent-based model and simulation based on empirical data collected by questionnaires. Simulation is a useful tool to investigate complex systems in many different fields such as engineering, physics, mathematics, and economics and is also becoming an increasingly significant methodological approach in organizations and strategy and public management field [11-16]. Among the different simulation models, the agent-based approach is very useful to investigate complex systems and networks characterized by a large number of simple interacting units [17-26]. An agentbased model provides a computational laboratory very suitable to make classical what-if analysis by means of experiments [27-33]. In organizations, field agent-based models (ABMs) are particularly well suited to study processes where heterogenous interacting entities are involved [34-37]. Thus, they represent a useful tool to investigate the effects of new policies such as new incentive mechanisms. In the following, Section 2 presents the literary review and the research gap, Section 3 the questionnaire data, Section 4 the simulation model, Section 5 the computational experiments, and Section 6 the empirical analysis. Finally, Section 7 provides the discussion and conclusions of the study.

\section{Literature Review and Research Question}

In the literature, many studies about the increasing of efficiency and performance of the PA have been presented [38]. Usually, the organizational performance is considered directly related to the performance of employees, and how to evaluate the performance of employees in the public sector is an interesting and difficult field of research [39-42]. The main theories consider jointly the "capacity to work" and the "will to work" to determine the employees' performance $[43,44]$. The "capacity to work" has been formalized as ability, whereas the "will to work" as motivation [45]. Some years later, to improve the effective evaluation of the employees' contribution, the Ability, Motivation, and Opportunity model (AMO model), which adds the "opportunity to perform" to the "capacity to work" and "will to work," has been defined [46, 47]. According to this theory, Human Research (HR) system is viewed as a composition of employee skills, motivation, and opportunity to contribute in working life [46, 48-52].

2.1. Monetary Reward. It is already known that the economic motivation is one of the most used stimuli to improve the firm performance $[53,54]$. Focusing on the relation between monetary incentives and employees' performance, one of the most important theories is Performance Related Pay (PRP) theory, derived from the principles of Weberian bureaucracy, see [55], for further details. With respect to a system that grants a bonus based on seniority, PRP is a mechanism able to quickly increase work motivation and improve the performance of employees [56]; in fact employees work harder if they, valuing the monetary rewards, trust that those awards are related to their increased efforts $[57,58]$.

In the literature, the use of financial incentives and in particular of monetary incentives is based primarily on the theoretical propositions of reinforcement theory [59] and expectancy theory [60]. Reinforcement theory, premised on the principles and techniques aimed at modifying organizational behavior, investigates the connection between the target behavior (e.g., performance) and the motivational tool (e.g., pay for performance) [61-63], whereas expectancy theory is an analytical tool to study how a reward system motivates the employees [64].

Other theories useful to investigate the link between incentives and motivation are the equity theory and the distributive justice. According to the equity theory, each employee compares her/his contribution to the organization with the reward gained by her/his job [65] and with the one obtained by other coworkers. Instead the idea of distributive justice is connected to the one of procedural justice. According to procedural justice, individuals evaluate the mechanism that the organization introduces to distribute rewards [66].

Several studies in the literature state that the efficacy of monetary incentives is connected to specific conditions of organizations. In particular, they argue that individual economic incentives are not so useful in the traditional public sector, if the medical and educational contexts are excluded [54, 59, 67-71].

In particular, a study focused on public managers reports that financial rewards had no significant effect on the managers' effort [72]. It is worth noting that the relationship between incentive and performance in public and private sector has different peculiarities mainly due to specificity of cultural dimension, market relations, bonus size, and nonexpandable business constraints $[67,73]$. Finally, in the PA, the link between incentive and performance is not straightforward because it is difficult to identify the contribution of each employee. In fact, in private firms, this is easier because the results of operations are quantitatively measurable, whereas in the public sector, where profit is not the primary target, this is more difficult. Thus, an evaluation schemes, designed to capture the different levels of competence and predisposition of individuals to make a greater effort in the workplace, can be adopted.

2.2. Research Gap. In this paper, the employees' performance is evaluated focusing on their abilities and motivations. Many mechanisms can be used to detect the abilities of employees [74], but all of them can be attributed to two fundamental models: the subjective evaluations, that consider the individual organizational behavior, and the objective evaluations, that directly take into account the feedback of one or more superior or all of the colleagues. 
Focusing on the objective evaluation, the network analysis, mainly focused on the links among the employees, allows to evaluate the importance and relevance of each employee, with respect to her/his colleagues. Indeed, the relationships, in the informal network, reflect the recognition given to a single employee from their colleagues for her/his skills and her/his opportunities to participate in working life.

The ability is also a measure of employees to make themselves available by their colleagues $[75,76]$.

The motivation is reflected considering a model with different levels of stimuli that depend on the employees' strength and successes. They are represented by the achievement of a predetermined threshold that leads to different monetary rewards [77]. This model is based on the expectancy theory of motivation, a process theory that provides an explanation of individual criteria used to choose among different behaviors. According to this theory, the work motivation depends on the perceived association between performance and outcomes. Employees modify their behavior based on their estimation of anticipated outcomes [78]. According to [79], the motivation for work is related to a series of causes and effects: first of all persons should trust that their increased efforts will translate into a better performance; secondary, a satisfactory performance should lead to a wanted reward; thirdly, the reward should fulfill a significant need for the individual. Finally, the desire to fulfill this need should be strong enough to make the initial efforts worthwhile.

So far, in the PA, the financial incentives are distributed among the employees following a hierarchical mechanism, without considering the performance of each employee. Specifically, the incentives are first uniformly distributed among the business units and then subdivided among individual employees. The portion of incentives received by each employee is proportional to its tenure, i.e., related to the role in the organization, not determined by its performance.

As mentioned in the introduction, the Italian D.L.150/09 tried to introduce a merit logic in the distribution of monetary incentives in the PA. According to the D.L.150/09, the bonus is evaluated with a merit logic, which is formalized by the closed rank tournament theory, which means that the employees are ranked and only a subset takes the monetary incentives according to the employees' performance. According to this law the employees are divided in three sets, called set A, B, and $\mathrm{C}$, and receive a different amount of monetary incentives according to the set. In particular, 25\% of the total employees is collocated in set A, $50 \%$ in set B, and $25 \%$ in set $C$. The total amount of monetary incentives is divided as follows: $50 \%$ to set $\mathrm{A}, 50 \%$ to set $\mathrm{B}$, and $0 \%$ to set C. Thus, people in set $\mathrm{C}$ do not receive any kind of monetary incentives.

The main research question of the paper is to investigate if the monetary incentives, distributed according to merit criteria, i.e., according to D.L. 150/09, are a stimulus for better performance in the short, middle, and long term. The effect of the introduction of D.L.150/09 is investigated considering the sustainability of the new rules for the distribution of incentives along time using the agent-based simulation. The simulation verifies if the monetary incentives distributed with merit criteria have positive or negative effect after the introduction of the rule. In detail, the sustainability of the merit criteria in the distribution of monetary incentives is investigated considering how many employees every year are in the same set and how many employees change set trying to improve their performance.

\section{The Data}

A series of interviews has been arranged in order to explore the connection between the performance of the employees and the allocation of economic incentives: in February 2011, 131 employees were interviewed, and in January 2013, the arranged interviews were 126 . The interviews consisted of one hour face-to-face sessions composed of 57 questions, to which the employees had to respond with a value between 1 and 7, according to the Likert scale [80]. The employees interviewed belong to five different organizational areas. In order to minimize misunderstandings, the research team directly administered the questionnaires. The questionnaires were anonymous, the provided data were only used for private purposes, and the people were interviewed in agreement with the trade unions. In February 2011, 126 questionnaires were collected out of 131 (four employees were absent in that period, and one was hired as a temporary secretary). In 2013, interviewees were 123 out of a total of 126. The total number of employees decreased because there have been a few retirements, and, due to the financial crisis, the assumption rate was lower than the retirement rate. The questionnaires were composed of four different sections:

(i) Personal data (gender and age)

(ii) Position (tenure and organizational area)

(iii) Skills (problem solving, teamwork, determination, customer oriented, and self-organization)

(iv) Intraorganization relationship

The resultant set of data provides information on both employee characteristics (occupied position, knowledge, skills, and background) and the organizational model (the relationships maintained between employees of the same organization and between different organizations). In addition to this data, the HR department provided the salary information of employees for the three years from 2010 to 2012. Specifically, this information included

(i) The uniformly distributed portion of the bonus granted to every employee

(ii) The portion of the bonus based on the criteria of merit

(iii) The salary-level: there are 12 levels, 8 of which are reserved for employees having nonexecutive positions

It is worth noting that, in 2010, the total amount of incentives distributed equally among the business units was $47 \%$ and the one distributed according the merit criteria was $53 \%$, whereas in 2011 , the allocation was $36 \%$ and $64 \%$, respectively. Thus, the monetary incentives distributed according the merit criteria increases from 53\% to $64 \%$. 


\section{The Model}

4.1. The Network. The employees in the model are organized as a directed graph, where the employees are the nodes and the arrows represent the interactions among employees. The total number of employees is $N$ and each employee is characterized by an identification number id. An employee is linked to a set of other employees whose number and strength (of the connection) $g_{i j}$ depends on the real data. The connections among the employees have been determined ignoring the vertical relation among supervisors and employees and considering the informal network created by means of the information obtained with the administered questionnaire. In fact, employees were asked with whom and how many times they need to interact to perform the given task. In particular, they had to indicate up to ten members of the organization they need to relate more directly and more frequently with, in order to improve or facilitate the execution of their activities. In order to quantify the frequency of the connection, i.e., the strength, a Likert scale that ranges from 1 (contacts infrequent, some once a month) to 7 (several times per day) has been used. With the collected information, an adjacency, squared, and not symmetrical matrix has been built and shown in the informal network of Figure 1. It is worth remarking that only the connections between employees in the same level have been considered, to find out only the "horizontal" relationships.

The interactions in the graph are assumed to be unidirectional (i.e., if employee $j$ influences employee $i$, it does not necessarily mean that employee $i$ influences employee $j$ ) and characterized by a weight $g_{j i}$, assumed a positive real number in the range $[0,1]$ proportional to the Likert scale. As a directed graph is used, both an output and input node degrees are defined. The output node degree is associated to the output branches of a given node, whereas the input node degree is related to the input arrows.

Furthermore, each employee is characterized by her/his rank $r$ and her/his performance $P$.

At each time step $h$, the performance of employee $i$ is evaluated and the rank $r_{i}^{h}$ is updated. The agent's rank $r$ is an integer number between 1 and 3 depending on the set to which the employee belongs. Employees in set A have rank $r_{i}^{h}=1$, in set $\mathrm{B}$ have rank $r_{i}^{h}=2$, and in set $\mathrm{C}$ have rank $r_{i}^{h}=3$. According to their performance, in descending order, the employees are divided in three set: A, B, and C. Set A is formed by the top $25 \%$ of the total employees, set B by the next $50 \%$, and set $C$ by the last $25 \%$ (see D.L. 150/09, for more details). It is worth remembering that employees belonging to different sets receive a different fraction of monetary incentives. In particular, half of the total amount of monetary incentives is divided among employees in set A, half among employees in set B, and 0 among employees in set C.

The graph is responsible for the changes in employees' rank. In fact, at each time step, employees depending on their rank change a fraction of his/her connections in order to improve the performance.
4.2. The Performance. As already stated in Section 2, the performance is a function of Ability and Motivations and quantitatively the performance is measured as the production of ability and motivation [43]. In formulas,

Performance $=$ Ability $\times$ Motivation .

4.2.1. Ability. As already stated in Section 2, in order to detect the abilities of employees, the objective evaluations have been considered by using the network analysis approach. Generally speaking, the influence of an individual regarding other individuals within a network is indicated by his/her centrality [81].

Centrality in the advice network means the recognition given to a single employee from her/his colleagues for the availability in exchanging advices and in problem solving. A central individual can increase knowledge about different problems over the years, and as more and more colleagues become dependent on her/him for some help, she/he gains power and authority $[82,83]$. There are many definitions of centrality, but the most common are the Degree, the Closeness, the Betweenness, the Coreness, and the Bonacich centrality [84-87].

In this paper, among the others the degree centrality is chosen and the centrality is measured by means of the number of connections among the employees, defining the centrality index.

The centrality index of employee $i, \mathrm{CI}_{i}$, indicates the relationship between employee $i$ and the other employees and, in particular, quantifies how employee $i$ is involved in the activities of the other employees:

$$
\mathrm{CI}_{i}=\frac{\mathrm{TAC}_{i}}{c_{\max }}
$$

where $\mathrm{TAC}_{i}$ is the task advice centrality of employee $i$ and $c_{\max }$ is the maximum number of input connections among all the employees. The task advice centrality for each node, i.e., the centrality of the individual in the social consulting network, is the sum of all incoming arrows (input node degree) multiplied by their weights. As mentioned above, the employee's centrality in the intraorganizational network reflects her/his skills to participate in working life and, in particular, indicates how a node is necessary to perform the employees' activities. Thus, it is a proxy of the employees' ability. In the formula, the task advice centrality of employee $i\left(\mathrm{TAC}_{i}\right)$ is

$$
\mathrm{TAC}_{i}=\sum_{j} c_{j, i} g_{j, i},
$$

where $c_{j, i}$ are the incoming arrows of employee $i$ and $g_{j, i}$ are the respective weights.

4.2.2. Motivation. As stated in Section 2, the expectancy theory of motivation has been considered. According to this theory, employees can be motivated if they believe that there is a positive correlation between efforts and performance. This behavior has been schematized defining the motivation 


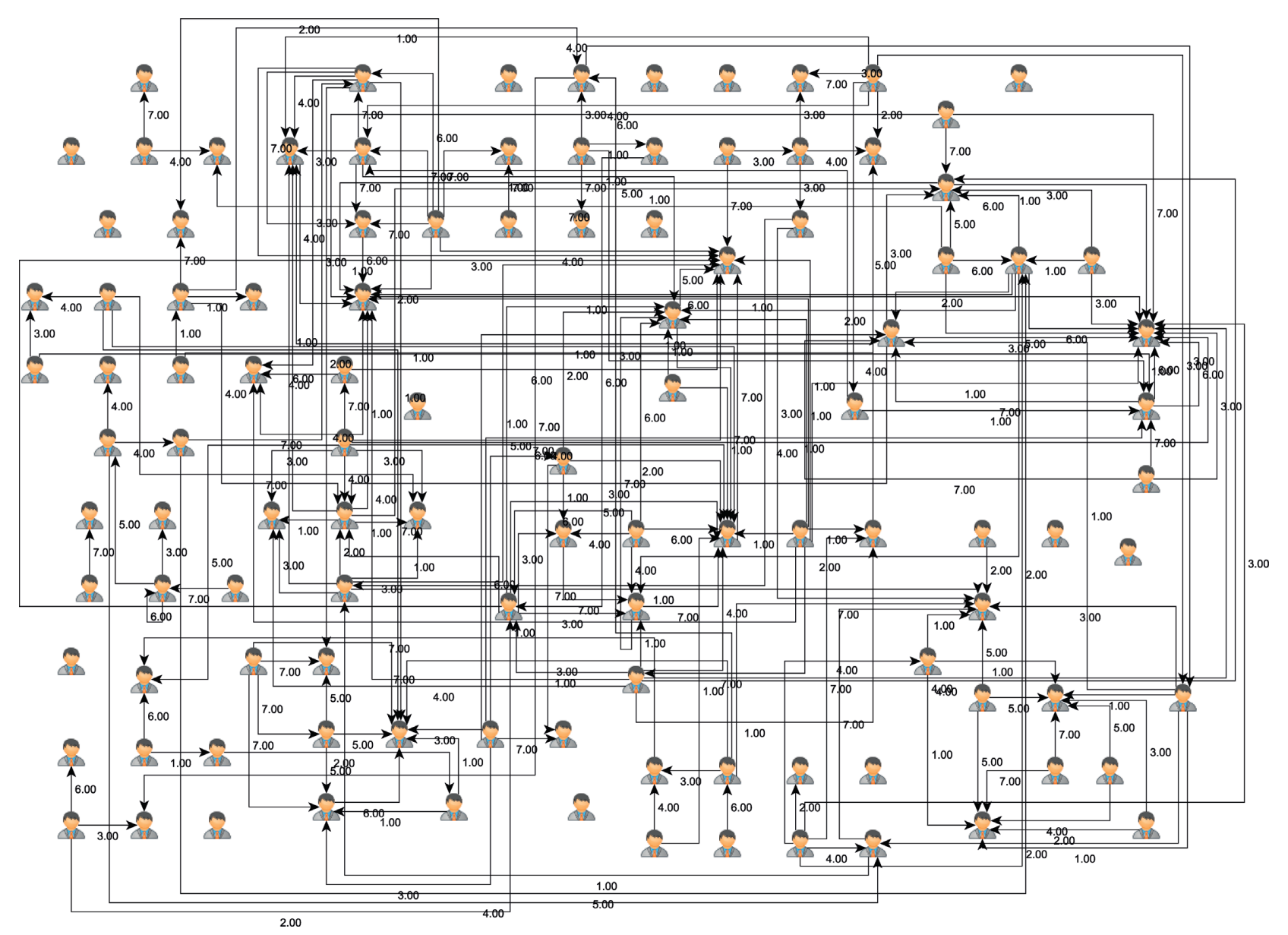

Figure 1: Network of employees at time $t=0$.

index MI. In particular, the motivation of employee $i$ is quantified with the motivation index $\mathrm{MI}_{i}$. According to D.L. $150 / 09$, the employees are ranked and divided in three sets A, $\mathrm{B}$, and $\mathrm{C}$ and receive a different fraction of monetary incentive. In particular, $25 \%$ of the total employees is collocated in set $\mathrm{A}, 50 \%$ in set $\mathrm{B}$, and $25 \%$ in set $\mathrm{C}$, respectively, whereas half of the total amount of monetary incentives is divided among employees in set $\mathrm{A}$, half among employees in set $\mathrm{B}$, and 0 among employees in set $\mathrm{C}$. The motivation index quantifies the motivation of each employee to do better in order to receive more monetary incentive. According to the deprivation-satiation proposition, the more often in the recent past a person has received a major award, the less he will confer a value to any further reward. Following this proposition, for employees in set A (corresponding to high incentives), the motivation decreases, increasing the performance evaluation, and conversely, for employees in set C, the motivation increases if performance evaluation increases. In particular, the employees near the upper bound of set $\mathrm{A}$ and the lower bound of set $\mathrm{C}$ are not motivated to do better [88]. In the formula, the motivation index $\mathrm{MI}_{\mathrm{A}}$ in set $\mathrm{A}$ is

$$
\mathrm{MI}_{A}=\frac{\left|E_{s}-P\right|}{\left(E_{s}-T_{a}\right)},
$$

where $E_{s}$ is the maximum value of performance in set $\mathrm{A}, T_{a}$ the minimum value of performance in set $\mathrm{A}, P$ is the employee performance, and the motivation index in set $C$, and $\mathrm{MI}_{\mathrm{C}}$ is

$$
\mathrm{MI}_{\mathrm{C}}=\frac{\left|P-E_{i}\right|}{\left(T_{b}-E_{i}\right)},
$$

where $E_{i}$ is the minimum value of rank in set $C$ and $T_{b}$ the maximum value of rank in set $C$. For employees in set $B$, the motivation is high when the employee is near the two bounds of the range and decreases in the middle. This is in line with the theory that while choosing among different actions, an employee chooses the one for which the results multiplied by the probability of getting it is greater [88]:

$$
\mathrm{MI}_{\mathrm{B}}=\frac{\left|T_{m b}-P\right|}{\left(T_{a}-T_{b}\right) / 2},
$$

where $T_{m b}$ is the middle value of rank in set B. Table 1 summarizes the parameters abbreviations.

Figure 2 shows how the motivation index MI ranges along the set $\mathrm{A}, \mathrm{B}$, and $\mathrm{C}$.

Employees in set $\mathrm{A}$ increase their motivation moving their level of assessment from $E_{s}$ (maximum level of assessment) to $T_{a}$. Employees in set $\mathrm{C}$ decrease their motivation moving their level of assessment from $T_{b}$ to $E_{i}$ 
TABLE 1: Description of the simulation model's parameters.

\begin{tabular}{lc}
\hline Abbreviation & Parameter \\
\hline CI & Network centrality index \\
MI & Motivation index \\
$E_{s}$ & Upper bound of set A \\
$T_{m a}$ & Middle value of set A \\
$T_{a}$ & Lower bound of set A and upper bound of set B \\
$T_{m b}$ & Middle value of set B \\
$T_{b}$ & Lower bound of set B and upper bound of set C \\
$E_{i}$ & Lower bound of set C \\
$P$ & Performance \\
\hline
\end{tabular}

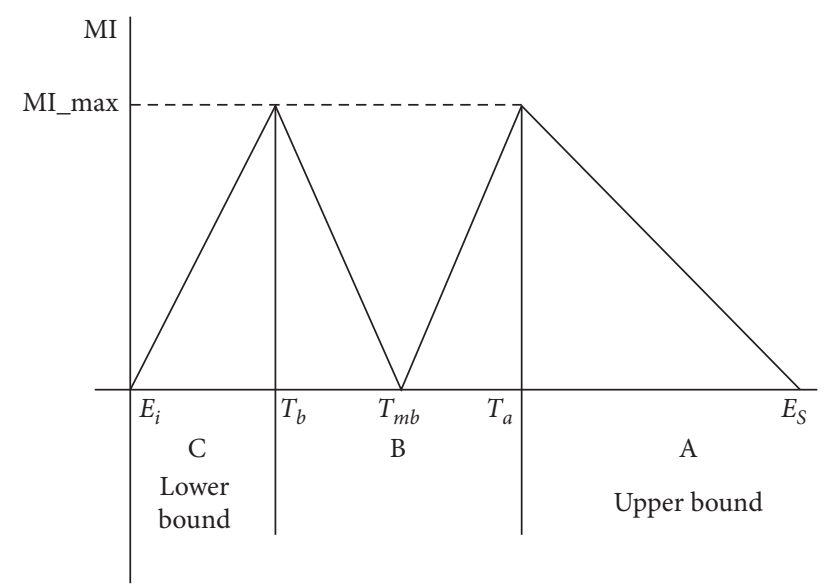

Figure 2: Motivation index.

(minimum level of assessment). Finally, in set B, employees' motivation tends to increase as their level of assessment is close to $T_{a}$ and $T_{b}$ and is minimum at the midpoint of the range $T_{m b}$.

Then, employee $i$ has a motivation $\mathrm{MI}_{\mathrm{A}, i}$ if his rank value belongs to set $\mathrm{A}, \mathrm{MI}_{\mathrm{B}, i}$ if it belongs to set $\mathrm{B}$, and $\mathrm{MI}_{\mathrm{C}, i}$ if it belongs to set $\mathrm{C}$.

4.2.3. Performance Calculus. In the model, the ability is approximated quantitatively with the centrality index (CI), which considers the relations among the employees, i.e., the informal network, whereas the motivation with the motivation index (MI). follows:

Thus, the performance of employee $i$ is evaluated as

$$
P_{i}=\mathrm{CI}_{i} \times \mathrm{MI}_{i}
$$

where $\mathrm{CI}_{i}$ is the centrality index and $\mathrm{MI}_{i}$ the motivation index. It is worth remarking that the performance is considered as the product of centrality index (that is a proxy of ability) and motivation index (that is a proxy of motivation).

\section{Computational Experiments}

In the computational experiments, the number of agents considered is 110 . Figure 1 shows the network of employees at time $t=0$, which corresponds to the empirical data, whereas Figure 3 zooms the connections of employee 61 at time $t=0$.

The simulation duration is twenty years $(T=20)$, in order to consider the short, middle, and long term. According to the empirical data, the number of ranks is three. The strength of each connection $g_{i, j}$ between two employees is a real number in the range $[0,1]$. The number of employees in set $\mathrm{A}$ is fixed to 35 , in set $\mathrm{B}$ to 70 , and in set $\mathrm{C}$ to 5 , whereas the total amount of incentives is divided in $47 \%$ for employees in set A, 52\% for employees in set B, and $1 \%$ for employees in set $\mathrm{C}$. It is worth noting that these values are different from the ones defined by D.L.150/09 because in the computational experiments the used values correspond to the empirical data. Table 2 summarizes the parameters used in the simulations.

At each time step that corresponds to a year, employees with rank 1, 2, and 3 change randomly from a uniform distribution $10 \%, 20 \%$, and $30 \%$ of their connections, respectively. This assumption mimics the realistic behavior of employees; in fact, employees in set $\mathrm{C}$ change more connections than employees in set $\mathrm{A}$ and $\mathrm{B}$ because in order to improve the performance they contact new employees, whereas employees in set A change very few connections because they do not need to contact new employees to improve their performance. Figures 4-7 show in the top the rank story and in the bottom the performance of agent 9, 103, 119, and 108 during the simulation, exhibiting the different behaviors of employees.

Figure 4 shows an employee who does not change his/her rank during the twenty years. In this case, the monetary incentives system does not work as stimulus to improve his/ her performance. Figure 5 shows the rank behavior of an employee that is not able to improve his/her performance, i.e., the performance worsens, and also in this case, the incentives' systems does not work, whereas Figure 6 shows the rank behavior of an employee who is able to improve his/ her performance, and therefore in this case, the incentives' systems work. Finally, Figure 7 shows the rank behavior of an employee with positive and negative changes. Also, in this case, the incentives' systems work as stimulus to improve the employees' performance.

Figure 8 shows the percentage of employees with different behaviors during the simulation.

In particular, the blue circle line represents the percentage of employees who are in set $\mathrm{A}$, the red dashed line the ones in set $\mathrm{B}$, and the black stair line the ones in set $\mathrm{C}$ who did not change set during the twenty years. The green triangle line represents the percentage of employees who during the twenty years worsened or not improved their rank position, whereas the cyan diamond line represents the ones who have improved or not worsened. Finally, the magenta continuous line represents the percentage of employees who during the simulation time improved or worsened their position. It is worth noting that the percentage of employees who did not change set along the twenty years decreases, whereas the number of employees who did not improve and the ones who did not worsen is constant. Instead, the percentage of employees who sometime improved and sometime worsened their rank increases 


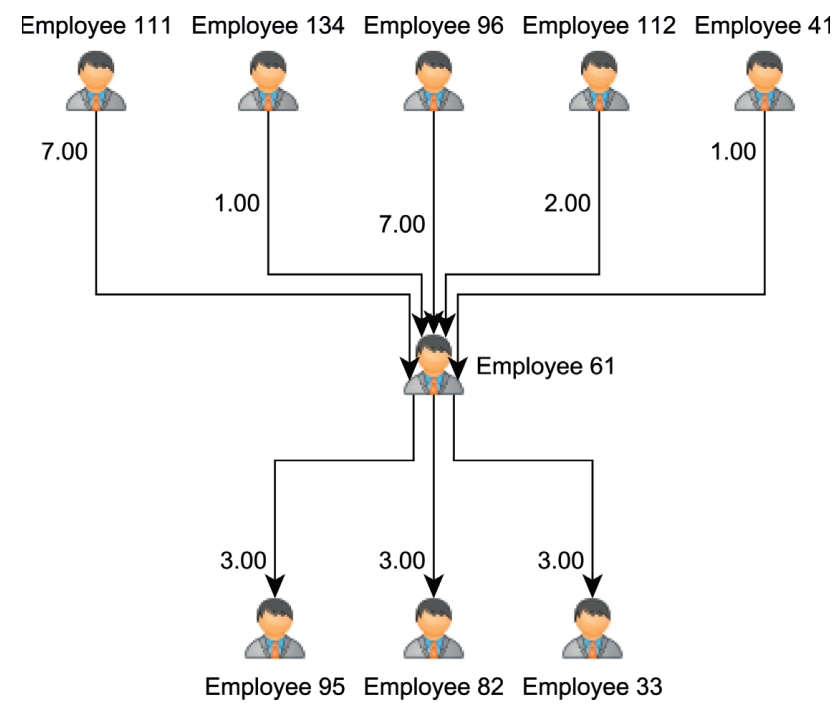

Figure 3: Zoom of connections of employee 61 at time $t=0$.

TABle 2: The most relevant parameter values used in the simulation.

\begin{tabular}{lcc}
\hline Symbol & Description & Value \\
\hline$N$ & Number of employees & 110 \\
$N_{\mathrm{A}}$ & Number of employees in set A & 35 \\
$N_{B}$ & Number of employees in set B & 70 \\
$N_{C}$ & Number of employees in set C & 5 \\
$T$ & Duration of simulation (years) & 20 \\
$R$ & Number of rank & 3 \\
$g_{i, j}$ & Strength of connections & {$[0,1]$} \\
\hline
\end{tabular}

along the twenty years. This means that, in the short term, people think that changes in the PA cannot be possible, as shown by the number of employees fixed in a set, whereas in the middle and long term the incentive system works because employees who try to improve their performance increase and the number of employees who are fixed in a set decreases.

Table 3 underlies the rank story of the employees in the simulation analysis $T=20$.

Figure 9 shows the percentage of employees for which the monetary incentives' mechanism works and did not work during the twenty years. The blue circle line represents the employees who are fixed in a set and the one that worsen their rank position. For these employees, the incentives' system does not work. The red stair line represents the employees who increase or increase and decrease their rank position. For these employees, the incentives' system works. It is worth noting that starting from year 12 (middle term) the percentage of employees which believes in the incentives' mechanism is larger than the one which does not. Moreover, this result confirms that the incentives distributed according to a merit approach bring to a better performance of employees and then of the firm in the middle and long term.

Finally, Figure 10 shows the analysis in the very short term, considering the behavior of employees rank and performance from year $t-1$ and $t$.
Figure 10(a) shows that, from year $t-1$ and $t$, the percentage of employees which does not change rank is between $85 \%$ and $95 \%$, whereas the number of employees which improves and the one which worsens rank is between $5 \%$ and $15 \%$ in both cases, whereas Figure 10(b) shows that the percentage of employees which does not change their performance is between $1 \%$ and $15 \%$ whereas the number of employees which improves and the one which worsens their performance is around $50 \%$ in both cases. This means that even if, in the short term, the number of employees which does not change rank is very large, the number of employees which does not change their performance is very few, showing that the employees try to improve also in the short term even if the results is visible only in the middle and long term. In the very short term employees move their performance, but this is not visible from the rank.

Finally, the analysis shows that the monetary incentives distributed according to a merit logic and the performance are linked in particular in the middle and long term simulation. In fact, in the middle and long term, the number of employees which does not change their rank decreases, confirming the positive effect of the incentives distributed with merit criteria. This means that the employees consider the incentives a good motivation for better performing. Moreover, in the short and very short term, the results suggest that, from a macropoint of view the employees think that changes in the PA are very difficult, but a deeper analysis shows that the employees' performance changes meaning which they try to improve in order to get a larger incentive. It is worth noting that the incentives distributed with merit logic bring the employees to a better individual performance and then to a better firm's performance. Thus, the hypothesis is confirmed in fact after $n$-step people continue to try to improve their performance.

\section{Empirical Analysis}

The computational results are confirmed in the short term by the empirical analysis on real data. Table 4 shows the same analysis performed for the computational experiments for the real data. In particular, the number of employees which is always in set $\mathrm{A}, \mathrm{B}$, or $\mathrm{C}$ and the ones which always worsens or improves or worse/improve their rank in year 2010/2011 and 2010/2012 are reported.

The results confirm the decreasing number of employees in a fixed set and the increasing number of the employees which improves and worsens their rank position. The number of employees which always improves or worsens remain more or less constant.

Concerning the very short term, Tables 5 and 6 show the employees' rank and performance in the period 2010/2011 and 2011/2012. The results confirm the computational experiments results.

\section{Discussion and Conclusions}

In this paper, the distribution of monetary incentives in the PA through a rank order tournament has been addressed. The relationship between the monetary incentives and 


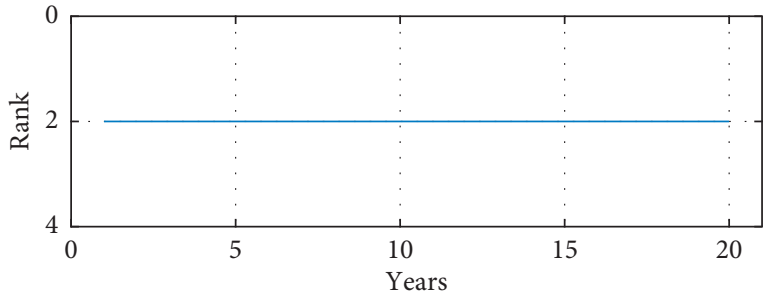

(a)

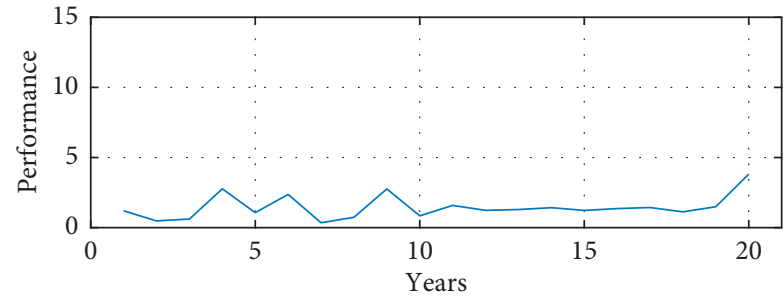

(b)

Figure 4: Rank history (a) and performance (b) of agent 9. During the simulation the employee 9 does not change his/her rank.

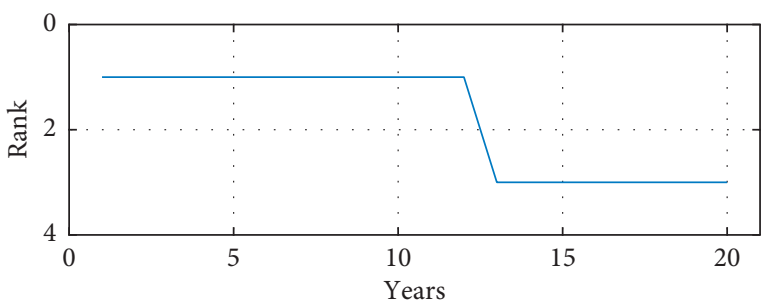

(a)

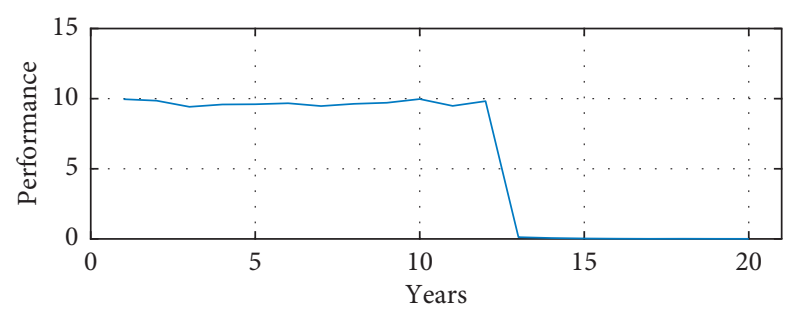

(b)

Figure 5: Rank history (a) and performance (b) of agent 103. During the simulation the employee 103 worsens his/her rank.

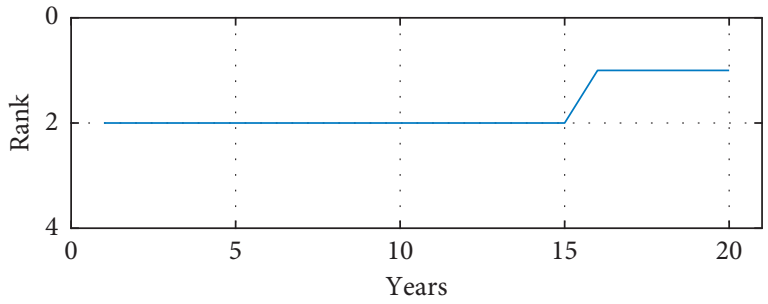

(a)

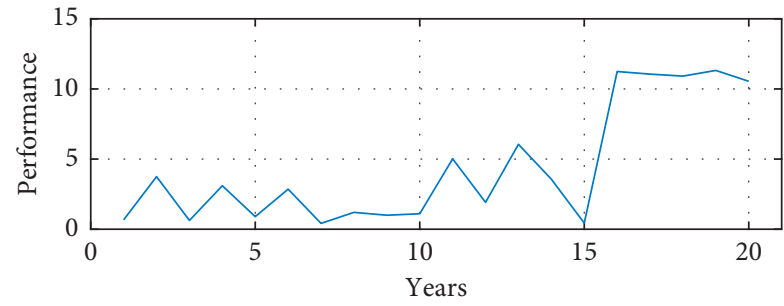

(b)

FIgURE 6: Rank history (a) and performance (b) of agent 119. During the simulation the employee 119 improves his/her rank.

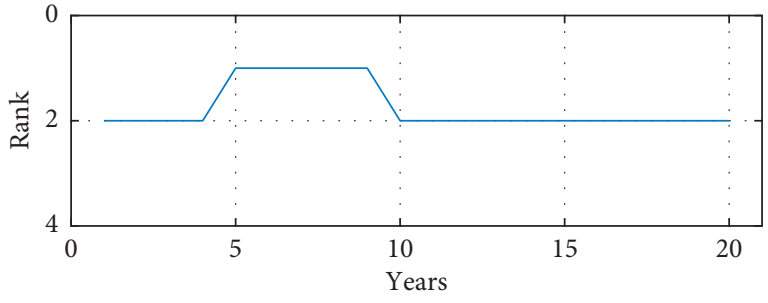

(a)

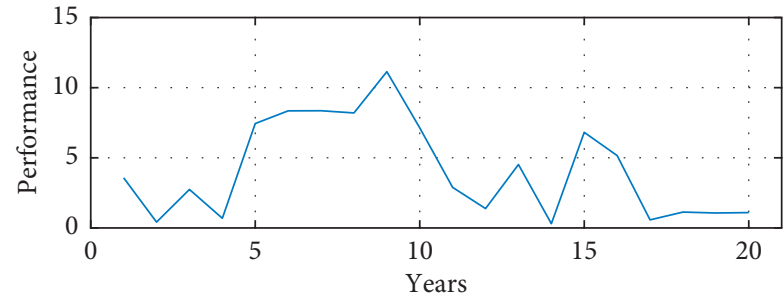

(b)

FIGURE 7: Rank history (a) and performance (b) of agent 108. During the simulation the employee 108 changes his/her rank.

performance of employees has been studied by mean of an empirical and computational approach. According to the classical literature, the proposed model incorporates two variables: the motivation and the ability. In particular, the employees' performance has been evaluated multiplying the motivation and the ability components, and the incentives have been distributed according to D.L.150/09 (the monetary incentives are divided among the employees with a logic that consider the employees' performance). The design of both employees' performance evaluation and monetary incentives distribution have been presented and discussed according to the theoretical and computational aspects.

The results have shown a modification of the employee's behavior according to both the theoretical foundations and the results discussed in $[89,90]$. Both the empirical and computational results show that the monetary incentives work as stimulus for employees to reach the maximum incentive and the mechanism is suitable during the years. It 


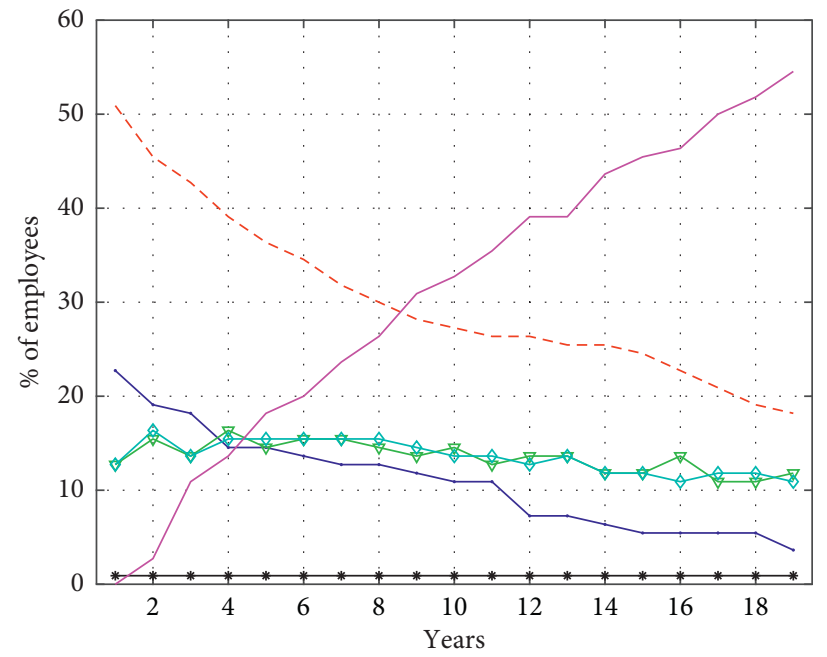

Figure 8: Percentage of employees with different behaviors during the simulation. The blue circle line represents the percentage of employees who are in set $\mathrm{A}$, the red dashed line represents the ones in set $\mathrm{B}$, and the black stair line represents the ones in set $\mathrm{C}$ who did not change set during the twenty years. The green triangle line represents the percentage of employees who during the twenty years worsened or not improved their rank position, whereas the cyan diamond line represents the ones who improved or not worsened. The magenta continuous line represents the percentage of employees who during the simulation time improved or worsened their position.

TABLE 3: Rank story of the employees. Number of employees who changed or did not change their rank during the twenty years simulation.

\begin{tabular}{lccccccc}
\hline Employees' set & $T=1$ & $T=2$ & $T=3$ & $T=4$ & $T=5$ & $T=10$ & $T=15$ \\
\hline A & 33 & 31 & 30 & 30 & 29 & 26 & 23 \\
B & 68 & 66 & 65 & 65 & 64 & 58 & 56 \\
C & 5 & 5 & 5 & 5 & 5 & 2 & 2 \\
Worsening rank & 2 & 4 & 5 & 5 & 6 & 12 & 2 \\
Improving rank & 2 & 4 & 5 & 5 & 6 & 12 & 14 \\
Worsening/improving & 0 & 0 & 0 & 0 & 0 & 0 & 13 \\
\hline
\end{tabular}

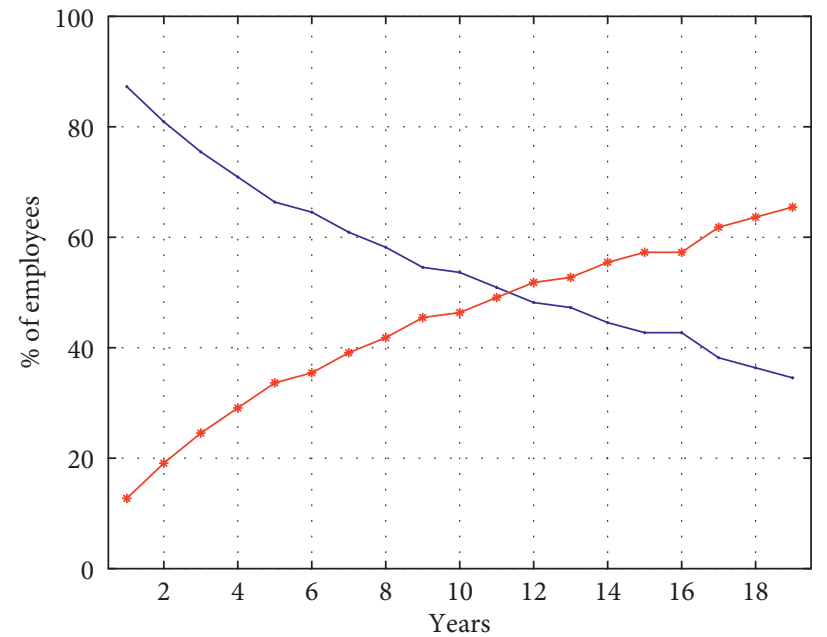

FIgURE 9: Percentage of employees for which the incentives' mechanism works in red star line and does not work in blue circle line.

is worth noting that, with the use of a rank order tournament mechanism, that is an ordinal system, to evaluate the performance of single employees, the result of the evaluation is known only at the end. This meritocratic system increases employee reactivity to managers' incitation, as suggested by the theory of social exchange [88]. Moreover, as discussed in $[91,92]$, the model implemented fits the fundamentals of a virtuous use of monetary incentives, such as the legitimacy of the appraisal, the objectivity of the criteria, and the possibility to achieve the initial goals at each repetition of the 


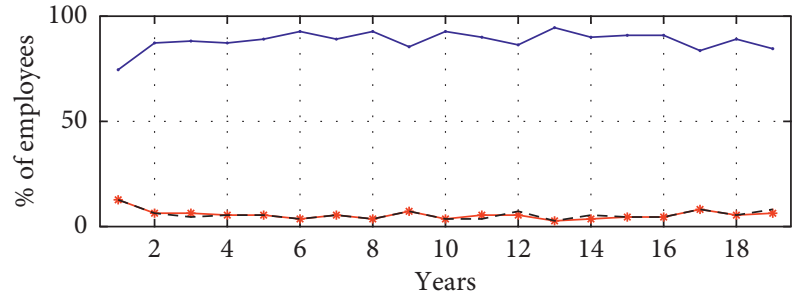

(a)

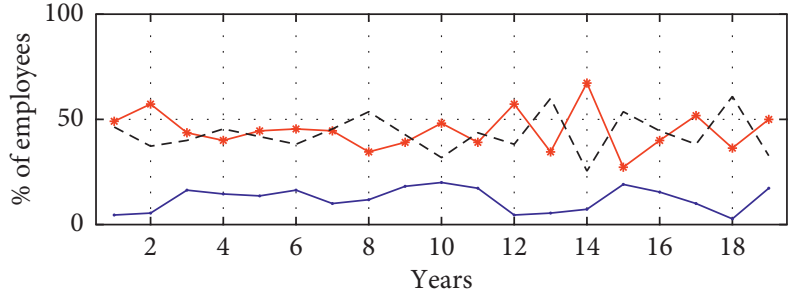

(b)

Figure 10: (a) \% of employees which does not change rank from $t-1$ to $t$ in blue circle line, \% of employees which improves rank position from $t-1$ to $t$ in black dashed, and \% of employees which worsens rank position from $t-1$ to $t$ in red star line. (b) \% of employees which does not change their performance from $t-1$ to $t$ in blue circle line, $\%$ of employees which improves their performance from $t-1$ to $t$ in black dashed, and \% of employees which worsens their performance from $t-1$ to $t$ in red star line.

TABLE 4: Rank story of the employees in the real case. Number of employees which changes or does not change their rank during the periods 2010/2011 and 2010/2012.

\begin{tabular}{lcc}
\hline Employees' set & $2010 / 2011$ & $2010 / 2012$ \\
\hline $\mathrm{A}$ & 26 & 23 \\
$\mathrm{~B}$ & 60 & 53 \\
$\mathrm{C}$ & 3 & 3 \\
Worsening rank & 11 & 14 \\
Improving rank & 12 & 12 \\
Worsening/improving & 0 & 7 \\
\hline
\end{tabular}

TABle 5: Rank story of the employees (real data). Number of employees which changes or does not change their rank during years 2010/2011 and 2011/2012.

\begin{tabular}{lcc}
\hline Employees' rank & $2010 / 2011$ & $2011 / 2012$ \\
\hline Fixed rank & 89 & 95 \\
Worsening rank & 11 & 10 \\
Improving rank & 12 & 7 \\
\hline
\end{tabular}

TABle 6: Performance story of the employees (real data). Number of employees which changes or does not change their performance during years 2010/2011 and 2011/2012.

\begin{tabular}{lcc}
\hline Employees' performance & 2010/2011 & 2011/2012 \\
\hline Fixed performance & 31 & 42 \\
Improving performance & 44 & 46 \\
Worsening performance & 37 & 24 \\
\hline
\end{tabular}

tournament. Furthermore, a study about various public companies in Britain has confirmed that employees' motivation is reduced if performance-based pay does not operate fairly [93]. Finally, results have shown that the monetary incentives distributed with a merit logic impact positively the firm performance in the short, middle, and long term. The main limitation of the study is that only one local PA has been considered to calibrate the model. In the near future, other PA will be considered to enrich the analysis and the simulation model. The developed agent-based model and simulator, where agents represent the employees, are one of the first attempts to provide a suitable tool to make managerial analysis. In particular, policy makers can use the developed tool to experiment different monetary incentives mechanisms in order to find the most convenient policy that allows to enhance the employee performance. In the end, it is worth remembering that the developed simulator is a useful tool not only for Public Administrations but also for private companies.

\section{Data Availability}

Personnel questionnaire data are subject to NDA and cannot be provided. Simulation data can be provided upon request.

\section{Conflicts of Interest}

The authors declare that there are no conflicts of interest regarding the publication of this paper.

\section{Acknowledgments}

The authors gratefully acknowledge Camera di Commercio di Genova for useful discussions.

\section{References}

[1] C. Pollitt and G. Bouckaert, Public Management Reform: A Comparative Analysis, Oxford University Press, Oxford, UK, 2004.

[2] M. Barzelay, Breaking through Bureaucracy: A New Vision for Managing in Government, University of California Press, Berkeley, CA, USA, 1992.

[3] N. Flynn, Public Sector Management, Sage, Thousand Oaks, CA, USA, 2007.

[4] W. J. Kickert, E.-H. Klijn, and J. F. M. Koppenjan, Managing Complex Networks: Strategies for the Public Sector, Sage, Thousand Oaks, CA, USA, 1997.

[5] C. Hood, "A public management for all seasons?" Public Administration, vol. 69, no. 1, pp. 3-19, 1991.

[6] C. Hood, "The "new public management" in the 1980s: variations on a theme," Accounting, Organizations and Society, vol. 20, no. 2-3, pp. 93-109, 1995.

[7] G. Gruening, "Origin and theoretical basis of new public management," International Public Management Journal, vol. 4, no. 1, pp. 1-25, 2001.

[8] J. Valasek, "Dynamic reform of public institutions: a model of motivated agents and collective reputation," Journal of Public, vol. 168, pp. 94-108, 2018. 
[9] A. B. Whitford, "Incentives and tournaments in public organizations," 2006, https://ssrn.com/abstract=873488.

[10] T. Eriksson and M. C. Villeval, "Performance-pay, sorting and social motivation," Journal of Economic Behavior \& Organization, vol. 68, no. 2, pp. 412-421, 2008.

[11] L. Ponta, A. Carbone, and M. Gilli, "Resistive transition in disordered superconductors with varying intergrain coupling," Superconductor Science \& Technology, vol. 24, no. 1, Article ID 015006, 2011.

[12] A. Teglio, A. Mazzocchetti, L. Ponta, M. Raberto, and S. Cincotti, "Budgetary rigour with stimulus in lean times: policy advices from an agent-based model," Journal of Economic Behavior \& Organization, vol. 157, pp. 59-83, 2019.

[13] M. Raberto, B. Ozel, L. Ponta, A. Teglio, and S. Cincotti, "From financial instability to green finance: the role of banking and credit market regulation in the Eurace model," Journal of Evolutionary Economics, vol. 29, no. 1, pp. 429-465, 2019.

[14] J. P. Davis, K. M. Eisenhardt, and C. B. Bingham, "Developing theory through simulation methods," Academy of Management Review, vol. 32, no. 2, pp. 480-499, 2007.

[15] D. C. Smith, "Making management count: a case for theoryand evidence-based public management," Journal of Policy Analysis And Management, vol. 28, no. 3, pp. 497-505, 2009.

[16] L. Iandoli, E. Marchione, C. Ponsiglione, and G. Zollo, "Learning and structural properties in small firms' networks: a computational agent-based model," Research in Economics and Business: Central and Eastern Europe, vol. 1, 2013.

[17] L. Fraccascia, I. Giannoccaro, and V. Albino, "Efficacy of landfill tax and subsidy policies for the emergence of industrial symbiosis networks: an agent-based simulation study," Sustainability, vol. 9, no. 4, p. 521, 2017.

[18] T. Wu, S. Huang, J. Blackhurst, X. Zhang, and S. Wang, "Supply chain risk management: an agent-based simulation to study the impact of retail stockouts," IEEE Transactions on Engineering Management, vol. 60, no. 4, pp. 676-686, 2013.

[19] M. A. Zaffar, R. L. Kumar, and K. Zhao, "Impact of interorganizational relationships on technology diffusion: an agent-based simulation modeling approach," IEEE Transactions on Engineering Management, vol. 61, no. 1, pp. 68-79, 2014.

[20] A. F. de Toni and F. Nonino, "The key roles in the informal organization: a network analysis perspective," The Learning Organization, vol. 17, no. 1, pp. 86-103, 2010.

[21] S. Pastore, L. Ponta, and S. Cincotti, "Heterogeneous information-based artificial stock market," New Journal of Physics, vol. 12, no. 5, Article ID 053035, 2010.

[22] L. Ponta, S. Pastore, and S. Cincotti, "Information-based multi-assets artificial stock market with heterogeneous agents," Nonlinear Analysis: Real World Applications, vol. 12, no. 2, pp. 1235-1242, 2011.

[23] L. Ponta, M. Raberto, and S. Cincotti, "A multi-assets artificial stock market with zero-intelligence traders," EPL (Europhysics Letters), vol. 93, no. 2, p. 28002, 2011.

[24] L. Ponta, E. Scalas, M. Raberto, and S. Cincotti, "Statistical analysis and agent-based microstructure modeling of highfrequency financial trading," IEEE Journal of Selected Topics in Signal Processing, vol. 6, no. 4, pp. 381-387, 2012.

[25] L. Ponta and S. Cincotti, "Traders' networks of interactions and structural properties of financial markets: an agent-based approach," Complexity, vol. 2018, Article ID 9072948, 9 pages, 2018.

[26] L. Ponta, S. Pastore, and S. Cincotti, "Static and dynamic factors in an information-based multi-asset artificial stock market," Physica A: Statistical Mechanics and Its Applications, vol. 492, pp. 814-823, 2018.

[27] B. Vermeulen and M. Paier, Innovation Networks for Regional Development: Concepts, Case Studies, and Agent-Based Models, Springer, Berlin, Germany, 2016.

[28] R. Axelrod, The Complexity of Cooperation: Agent-asedModels of Competition and Collaboration, vol. 3, Princeton University Press, Princeton, NJ, USA, 1997.

[29] R. Axelrod, "Chapter 33 agent-based modeling as a bridge between disciplines," Handbook of Computational Economics, vol. 2, pp. 1565-1584, 2006.

[30] J. M. Epstein, Generative Social Science: Studies in AgentBased Computational Modeling, Princeton University Press, Princeton, NJ, USA, 2006.

[31] N. Gilbert and P. Terna, "How to build and use agent-based models in social science," Mind \& Society, vol. 1, no. 1, pp. 57-72, 2000.

[32] A. Pyka and T. Grebel, Agent-Based Computational Modelling, Springer, Berlin, Germany, 2006.

[33] M. Wooldridge, “Agent-based computing," Interoperable Communication Networks, vol. 1, pp. 71-98, 1998.

[34] D. Helbing, Social Self-Organization: Agent-Based Simulations and Experiments to Study Emergent Social Behavior, Springer, Berlin, Germany, 2012.

[35] B. J. L. Berry, L. D. Kiel, and E. Elliott, "Adaptive agents, intelligence, and emergent human organization: capturing complexity through agent-based modeling," Proceedings of the National Academy of Sciences, vol. 99, no. 3, pp. 7187-7188, 2002.

[36] J. Grundspenkis, “Agent based approach for organization and personal knowledge modelling: knowledge management perspective," Journal of Intelligent Manufacturing, vol. 18, no. 4, pp. 451-457, 2007.

[37] G. Fioretti, "Agent-based simulation models in organization science," Organizational Research Methods, vol. 16, no. 2, pp. 227-242, 2013.

[38] R. D. Behn, "The big questions of public management," Public Administration Review, vol. 55, no. 4, pp. 313-324, 1995.

[39] P. M. Wright, T. M. Gardner, and L. M. Moynihan, "The impact of HR practices on the performance of business units," Human Resource Management Journal, vol. 13, no. 3, pp. 21-36, 2003.

[40] M. A. Youndt, S. A. Snell, J. W. Dean, and D. P. Lepak, "Human resource management, manufacturing strategy, and firm performance," Academy of Management Journal, vol. 39, no. 4, pp. 836-866, 1996.

[41] T. Boland and A. Fowler, "A systems perspective of performance management in public sector organisations," International Journal of Public Sector Management, vol. 13, no. 5, pp. 417-446, 2000.

[42] S. Brignall and S. Modell, "An institutional perspective on performance measurement and management in the "new public sector"” Management Accounting Research, vol. 11, no. 3, pp. 281-306, 2000.

[43] C. A. Mace, "Incentives. Some experimental studies," Industrial Health Research Board Report, Medical Research Council, London, UK, 1935.

[44] M. S. Viteles, Motivation and Morale in Industry, NYC Norton, Jersey City, NJ, USA, 1953.

[45] N. R. F. Maier, Psychology in Industry: A Psychological Approach to Industrial Problems, Houghton Mifflin, Boston, MA, USA, 1955. 
[46] E. Appelbaum, Manufacturing Advantage: Why High-Performance Work Systems Pay Off, Cornell University Press, Ithaca, NY, USA, 2000.

[47] J. Paauwe, "HRM and performance: achievements, methodological issues and prospects," Journal of Management Studies, vol. 46, no. 1, pp. 129-142, 2009.

[48] P. Boxall and J. Purcell, "Strategy and Human Research Management. Management, Work and Organisations Series," Palgrave Macmillan, Basingstoke, UK, 2008.

[49] J. E. Delery and J. D. Shaw, "The strategic management of people in work organizations: review, synthesis, and extension," in Research in Personnel and Human Resources Management, vol. 20, pp. 165-197, Emerald Group Publishing, Bingley, UK, 2001.

[50] H. C. Katz, T. A. Kochan, and M. R. Weber, "Assessing the effects of industrial relations systems and efforts to improve the quality of working life on organizational effectiveness," Academy of Management Journal, vol. 28, no. 3, pp. 509-526, 1985.

[51] D. P. Lepak, H. Liao, Y. Chung, and E. E. Harden, “A conceptual review of human resource management systems in strategic human resource management research," in Research in Personnel and Human Resources Management, vol. 25, pp. 217-271, Emerald Group Publishing, Bingley, UK, 2006.

[52] A. H. Brayfield and W. H. Crockett, "Employee attitudes and employee performance," Psychological Bulletin, vol. 52, no. 5, pp. 396-424, 1955.

[53] M. Bannò and F. Sgobbi, "Firm participation in financial incentive programmes: the case of subsidies for outward internationalisation," Journal of Policy Modeling, vol. 32, no. 6, pp. 792-803, 2010.

[54] L. B. Andersen, "Professional norms, public service motivation and economic incentives: what motivates public employees?" in Proceedings of the EGPA Conference 2007, Department of Political Science, University of Aarhus, Madrid, Spain, September 2007.

[55] C. Dahlström and V. Lapuente, Organizing Leviathan: Politicians, Bureaucrats, and the Making of Good Government, Cambridge University Press, Cambridge, UK, 2017.

[56] E. Chang, "Motivational effects of pay for performance: a multilevel analysis of a Korean case," The International Journal of Human Resource Management, vol. 22, no. 18, pp. 3929-3948, 2011.

[57] T. Lah and J. L. Perry, "The diffusion of the Civil Service Reform Act of 1978 in OECD countries: a tale of two paths to reform," Review of Public Personnel Administration, vol. 28, no. 3, pp. 282-299, 2008.

[58] J. E. Salzman, "Labor rights, globalization and institutions: the role and influence of the Organization for Economic Cooperation and Development," SSRN Electronic Journal, vol. 21, pp. 769-975, 2000.

[59] R. F. Durant, R. Kramer, J. L. Perry, D. Mesch, and L. Paarlberg, "Motivating employees in a new governance era: the performance paradigm revisited," Public Administration Review, vol. 66, pp. 505-514, 2006.

[60] J. L. Pearce and J. L. Perry, "Federal merit pay: a longitudinal analysis," Public Administration Review, vol. 43, no. 4, pp. 315-325, 1983.

[61] B. F. Skinner, "Contingencies of reinforcement," Encyclopedia of Pain, Springer, Berlin, Germany, 1969.

[62] F. Luthans, "The contingency theory of management," Business Horizons, vol. 16, no. 3, pp. 67-72, 1973.

[63] A. D. Stajkovic and F. Luthans, "A meta-analysis of the effects of organizational behavior modification on task performance,
1975-1995," Academy of Management Journal, vol. 40, no. 5, pp. 1122-1149, 1997.

[64] W. Van Eerde and H. Thierry, "Vroom's expectancy models and work-related criteria: a meta-analysis," Journal of Applied Psychology, vol. 81, no. 5, pp. 575-586, 1996.

[65] J. S. Adams, Advances in Experimental Social Psychology, Vol. 2, Elsevier, Amsterdam, The Netherlands, 1965.

[66] J. Greenberg, "Organizational justice: yesterday, today, and tomorrow," Journal of Management, vol. 16, no. 2, pp. 399432, 1990.

[67] J. L. Perry, T. A. Engbers, and S. Y. Jun, "Back to the future? Performance-related pay, empirical research, and the perils of persistence," Public Administration Review, vol. 69, no. 1, pp. 39-51, 2009.

[68] S. M. Davidson, L. M. Manheim, S. M. Werner, M. M. Hohlen, B. K. Yudkowsky, and G. V. Fleming, "Prepayment with office-based physicians in publicly funded programs: results from the Children's Medicaid Program," Pediatrics, vol. 89, no. 89, pp. 761-767, 1992.

[69] B. Dowling and R. Richardson, "Evaluating performancerelated pay for managers in the national health service," The International Journal of Human Resource Management, vol. 8, no. 3, pp. 348-366, 1997.

[70] J. D. Shaw, M. K. Duffy, A. Mitra, D. E. Lockhart, and M. Bowler, "Reactions to merit pay increases: a longitudinal test of a signal sensitivity perspective," Journal of Applied Psychology, vol. 88, no. 3, pp. 538-544, 2003.

[71] J. Cilliers, I. Kasirye, C. Leaver, P. Serneels, and A. Zeitlin, "Pay for locally monitored performance? A welfare analysis for teacher attendance in Ugandan primary schools," Journal of Public Economics, vol. 167, pp. 69-90, 2018.

[72] N. Belle and P. Cantarelli, "Monetary incentives, motivation, and job effort in the public sector," Review of Public Personnel Administration, vol. 35, no. 2, pp. 99-123, 2015.

[73] G. J. Miller and A. B. Whitford, "The principal's moral hazard: constraints on the use of incentives in hierarchy," Journal of Public Administration Research and Theory, vol. 17, pp. 213233, 2006.

[74] J. A. Marin-Garcia and J. M. Tomas, "Deconstructing AMO framework: a systematic review," Intangible Capital, vol. 12, no. 4, pp. 1040-1087, 2016.

[75] L. C. Freeman, "A set of measures of centrality based on betweenness," Sociometry, vol. 40, no. 1, pp. 35-41, 1977.

[76] P. Bonacich, "Power and centrality: a family of measures," American Journal of Sociology, vol. 92, no. 5, pp. 1170-1182, 1987.

[77] J. W. Atkinson, "Motivational determinants of risk-taking behavior," Psychological Review, vol. 64, no. 6, pp. 359-372, 1957.

[78] Y.-Y. Chen and W. Fang, "The moderating effect of impression management on the organizational politics-performance relationship," Journal of Business Ethics, vol. 79, no. 3, pp. 263-277, 2008.

[79] E. Lawler, L. Porter, and V. Vroom, Motivation and management Vroom's expectancy theory. Value based management website, https://www.valuebasedmanagement.net/methods_ vroom_expectancy_theory.html, 2009.

[80] G. Albaum, "The Likert scale revisited," Journal-Market Research Society, vol. 39, pp. 331-348, 1997.

[81] D. J. Brass and M. E. Burkhardt, "Centrality and power in organizations," Networks and Organizations: Structure, Form, and Action, vol. 191, pp. 198-213, 1992.

[82] T. T. Baldwin, M. D. Bedell, and J. L. Johnson, "The social fabric of a team-based M. B. A. Program: network effects on 
student satisfaction and performance," Academy of Management Journal, vol. 40, no. 6, pp. 1369-1397, 1997.

[83] K. S. Cook, R. M. Emerson, M. R. Gillmore, and T. Yamagishi, "The distribution of power in exchange networks: theory and experimental results," American Journal of Sociology, vol. 89, no. 2, pp. 275-305, 1983.

[84] R. Aalbers and W. Dolfsma, Innovation Networks: Managing the Networked Organization, Routledge, Abingdon, UK, 2015.

[85] L. Lü, T. Zhou, Q.-M. Zhang, and H. E. Stanley, "The H-index of a network node and its relation to degree and coreness," Nature Communications, vol. 7, no. 1, p. 10168, 2016.

[86] M. Kitsak, L. K. Gallos, S. Havlin et al., "Identification of influential spreaders in complex networks," Nature Physics, vol. 6, no. 11, pp. 888-893, 2010.

[87] J. Boissevain and J. C. Mitchell, Network Analysis: Studies in Human Interaction, Walter de Gruyter GmbH \& Co KG, Berlin, Germany, 2018.

[88] G. C. Homans, Social Behavior: Its Elementary Forms, Revised, Ed., Harcourt, Brace and World, Inc., New York, NY, USA, 1974.

[89] G. C. Cainarca, F. Delfino, and L. Ponta, "The effect of monetary incentives on individual and organizational performance in an Italian public institution," Administrative Sciences, vol. 9, no. 3, p. 72, 2019.

[90] L. Ponta, F. Delfino, and G. C. Cainarca, "The role of monetary incentives: bonus and/or stimulus," Administrative Sciences, vol. 10, no. 1, p. 8, 2020.

[91] C. R. Knoeber and W. N. Thurman, "Testing the theory of tournaments: an empirical analysis of broiler production," Journal of Labor Economics, vol. 12, no. 2, pp. 155-179, 1994.

[92] S. Rosen, "Prizes and incentives in elimination tournaments," American Economic Review, vol. 76, no. 4, pp. 701-715, 1986.

[93] D. Marsden and S. French, "Performance pay in the United Kingdom," in Paying for Performance: An International Comparison, pp. 115-147, M.E. Sharpe, Armonk, NY, USA, 2002. 